\title{
The Perception and Degree of Adoption by Urbanites towards Urban Farming
}

\author{
Larisa Ivascu $^{1,2, * \mathbb{D}}$, David Frank Ahimaz $^{3}$, Benedict Valentine Arulanandam ${ }^{4} \mathbb{D}$ and Gelu-Ovidiu Tirian 5 \\ 1 Faculty of Management in Production and Transportation, Politehnica University of Timisoara, \\ 300191 Timisoara, Romania \\ 2 Academy of Romanian Scientists, 3 Ilfov str., 050044 Bucharest, Romania \\ 3 Jeffrey Sachs Center on Sustainable Development Management, Sunway University Business School, \\ Sunway University, Bandar Sunway 47500, Malaysia; david.ahimaz@gmail.com \\ 4 Sunway College, Victoria University, Bandar Sunway 47500, Malaysia; benedicta@sunway.edu.my \\ 5 Faculty of Engineering of Hunedoara, Politehnica University of Timisoara, 331128 Hunedoara, Romania; \\ ovidiu.tirian@upt.ro \\ * Correspondence: larisa.ivascu@upt.ro
}

check for updates

Citation: Ivascu, L.; Frank Ahimaz, D.; Arulanandam, B.V.; Tirian, G.-O The Perception and Degree of Adoption by Urbanites towards Urban Farming. Sustainability 2021, 13, 12151. https://doi.org/10.3390/ su132112151

Academic Editor: Spyros Fountas

Received: 7 September 2021

Accepted: 27 October 2021

Published: 3 November 2021

Publisher's Note: MDPI stays neutral with regard to jurisdictional claims in published maps and institutional affiliations.

Copyright: (c) 2021 by the authors. Licensee MDPI, Basel, Switzerland. This article is an open access article distributed under the terms and conditions of the Creative Commons Attribution (CC BY) license (https:// creativecommons.org/licenses/by/ $4.0 /)$.

\begin{abstract}
Malaysia is not shielded from the issues of food insecurity. Despite economic progression over the past few years, food insecurity is continuing to affect several vulnerable groups (Orang Asli, elderly, students, B40). It is a growing concern that should not be taken lightly, especially with the recent rise in food prices coupled with low income among vulnerable groups and the effects of the COVID-19 pandemic. As cities develop and expand, they stretch out and occupy former farmlands forcing farms to stop operating or move further off from the city centre. New trends like urban farming are slowly emerging, which have the potential to be a solution to the developing crises of food insecurity. This research aims to determine how relevant each of the factors, 'confidence' (CF), 'societal' (SC), 'pleasantness' (PL), and 'naturalness' (NT), are towards adopting (AD) the idea of urban farming and, if relevant, among which has the most positive impact. A mixed-method approach was used to obtain quantitative and qualitative data. One hundred and thirty-three responses were recorded and used (a significant sample size according to the G-power software). The validity and reliability of the data were also tested to affirm their quality and relevance according to the factors. The main findings revealed that 'pleasantness' and 'confidence' were strong factors for adopting urban farming, in line with Cohen's R Square of more than 32\%, which signifies a high impact toward influencing adoption. In addition, qualitative analysis shows that while positive outcomes complemented the quantitative study, practical constraints were highlighted. These constraints were space, time, supply chain, resources, tools, community and government support. Hence, this study provides two significant contributions to regulators and policymakers on urban farming (further explained in the discussions section).
\end{abstract}

Keywords: sustainability; urban farming; society; farm; urban; social responsibility

\section{Introduction}

To implement urban farming activities nationwide, it is essential to obtain stakeholders' perceptions and gauge what would drive them to adopt the idea of practicing urban farming. Some types of urban farming include community farms, and hydroponic/aquaponic systems. There are various reasons why people won't indulge in adopting urban farming, and it's fair to say that each person has their perception.

This research aims to determine how relevant each of the factors, 'confidence,' 'societal,' 'pleasantness,' and 'naturalness,' are towards adopting the idea of urban farming and which have the most positive impact. The research took place in the setting of the Klang Valley, an urban conglomeration in Malaysia. This area includes the capital city of Kuala Lumpur and its adjoining cities and towns in the state of Selangor. Practice theory is used in this study. 
Factors and variables from other studies were analysed to understand current notions surrounding this topic, primarily in Malaysia but also in different parts of the world.

In the last century, the world's population had significantly increased to about 7.7 billion people in 2019. It is estimated to grow to 9.7 billion in the year 2050 [1]. The food systems organised worldwide are not as efficient as they could be. Tremendous amounts of food are wasted every day (approximately one third of all food) in the food \& agricultural industry [2,3]. A significant portion of that wastage is due to poor logistics and the failure of outlets to sell everything. Wastage could further extend to include resources such as water, land, energy, and other natural resources used to produce food [4]. There are colossal amounts of wastage at procurement and selling sites, particularly in the fishing industries worldwide. Large amounts of by-catch (nontargeted species) are dumped on shores to die, and many non-fish species such as sea turtles and dolphins are killed due to lack of extruder devices. Furthermore, even targeted species are wasted due to the sheer numbers caught.

The dilemma here is that many of these resources can be used or sourced efficiently by modern urban farming techniques that mitigate land, water, and energy use, but this is not always done. Urban farmed fish and vegetables provide a controlled and targeted environment for minimum wastage. In trying times like these, can we afford more wastage with a fast-growing population? This is one of the reasons why the urban farming trend should be encouraged, and ways of promoting the movement should be studied. Furthermore, nearly $80 \%$ of Malaysians are expected to reside in urban areas by 2030 [5]. This could prove difficult for food supply logistics and increase prices of essential foods (i.e., rice, vegetables). These prices will increase as farms are pushed further away from urban areas, making the governments rely more on imports for food.

Malaysia is not entirely shielded from the harsh consequences of food insecurity. Several vulnerable groups exist in Malaysia (the elderly, Orang Asli, students, B40 communities). Recent effects of the COVID-19 pandemic have caused inflation in food prices, coupled with low income, which has made it increasingly difficult for these groups to obtain the right amount of essential foods that are nutritious, healthy, and affordable. Urban farming in such communities can be seen as a solution, but the trend needs to be strengthened, especially in the cities, where food security is likely to be threatened [2,5]. This study took place in the Klang Valley. The reason for selecting this location is because it has the largest concentration of locals present. In addition, many students and B40 community members reside here. It also includes cities such as the capital Kuala Lumpur (K.L) and Subang, Petaling Jaya, and several others.

According to research by the Food \& Agricultural Organisation (F.A.O.), and Jennings, Cottee, Curtis, and Miller [6] the rise in the world population and urbanization means more people to feed in a concentrated area. Food systems worldwide should be redesigned to be more centralised for logistically beneficial purposes to maintain food safety measures. Many newer industrial players are looking for fresh ways of establishing food networks in urban areas that grow and supply food. In Malaysia, there is CityFarm Malaysia, Plant Cartridge, UrbanFarmTech, Urban Hijau, and Sunway XFarms. These start-ups are gaining recognition and pioneering the effort on a commercial scale.

How are people moving along with these changes? Studies show that a shift in preferences to what people eat is changing as people become more environmentally and health-conscious. Major companies, for example, "Beyond meat" in the U.S, are pioneering foods that replace meat with plant-based "meat-like products" that have received generally good reviews, changing people's views on a vegetarian diet. There are many vegetarian food restaurants appearing in Malaysia. Opinions on the meat industry are changing as more people are educated with facts such as " $14.5 \%$ of all human-induced GHG (Green House Gas) emissions are from livestock, hence harmful to the environment" [7]. Fresh fruits and vegetables are becoming a part of the recent shift in preference here in Malaysia. They are not necessarily cheap, as prices have been increasing over the past years. Once 
again, this is due to several factors, a significant one being that they need to be imported or transported from afar, hence the high prices [8].

Why is urban farming a definite trend for sustainability? Where sustainability is concerned, plants are grown with modern farming methods; for example, hydroponics, as it saves water (70-90\%). Many hydroponics set-ups are also customisable, sustainable, and more easily implemented than traditional farming methods, provided there is the right expertise and equipment. Generally, in such systems, there is also less labour involved. There is no chance of soil-borne diseases, hence minimal insect or pest infections to the crops, resulting in less or no use of pesticides, and no toxicity. Certain plants tend to grow faster in comparison to crops grown in fields. Various large crops such as corn, maize, melons are not limited to the system and can be grown $[9,10]$. Numerous studies have shown that urbanisation comes with losses in local fauna and plants, all in a chain reaction wiping out a natural ecosystem bit by bit [11]. In aspiring to do urban farming on a larger scale, people not only mitigate the growing issue of food security but also bring back some of the nature lost from urbanisation.

The Malaysian government is taking steps to stimulate urban farming. For example, creating the urban agriculture division under the Department of Agriculture Malaysia in 2010 promoted agricultural activities in the city, all in an effort to reduce the cost of living of the urban community [12]. Nearly $40 \%$ of Malaysia's vegetable product imports are accounted for in corn, wheat, soybeans, and rice [13]. These are the staples that fuel our economy, the people and also contribute to feeding livestock. Most of these can be grown by urban farming. Alternatively, livestock feed can be replaced by urban-farmed soldier fly insects that are high in protein and are more beneficial. Furthermore, niche urban farming trends are emerging, replacing known ingredients with mass-produced insect-based components rich in nutrients (e.g., B12, iron, zinc, Vitamin A, unsaturated fatty acids, and proteins).

Some progress has been observed among people and communities embracing urban farming in Malaysia and even adapting to growing vegetables indoors. For instance, in the state of Selangor, there exist community farms in places like Subang Jaya and Petaling Jaya. Despite this, many Malaysians are still not exposed to urban farming or lack knowledge on how to set it up.

\section{Literature Review}

For this study, social practice theory was used as a lens to focus on all the data analysed. According to Spaargaren, Lamers [14], "All practice theories acknowledge the important, co-constituting role of material objects in social life. One cannot claim to use a practicebased approach when neglecting the role of material objects, symbols, things, technologies, and infrastructures as the necessary hardware of the social." Hence in this research, imagery of urban farming technology, and infrastructure were some of the essentials used in the questionnaire. Social practice theory's use is becoming more common with regards to studying people's changing behavior towards environmental sustainability. Furthermore, social practice theory tends to use networks of various "critical hardware" as to how the final goal is achieved.

A study byStrengers and Maller [15], outlines the concept of boundaries of social practice theory. People everywhere indulge in daily habits such as heading to a store to purchase food or a restaurant to eat. In this study, we seek which relevant factors most influence an urbanite living in the Klang Valley adopting the idea of urban farming. Adopting a new social practice tends to shift 'routine/habitual lifestyle' to adjust to the practice, allocating time accordingly. This is based on the fundamentals of social practice theory.

What are the variables that will strengthen the trend for society's transition into Urban Farming? We must seek alternatives to already established habitual behaviours such as going to the store to buy food or cooking certain types of food. Identifying the factors that have the strongest positive perceptions on urban farming and building on their common understandings, material infrastructures, or practical \& tacit knowledge and 
skills will likely establish new pathways to urban farming practices (e.g., urban farming communities) which will replace older habitual behavior, without involving any urban farming whatsoever.

These already established material infrastructures, practical and tacit knowledge and skills, and shared understandings must be replaced, carefully and appropriately, with solid and reliable alternatives. Based on people's perceptions, one can find clues and directions on how to transit their practices into that of urban farming. For example, industries in other Asian countries like India are moving towards eco-restoration within their factory estates (such as TVS, TATA, and Royal Enfield). They have rehabilitated parts of the land and restored an ecosystem for wildlife to thrive within the estate, with various measures to maintain harmony between nature and modern urbanization (the factories/buildings). Such practices could pave a path towards adopting urban farming. Hence, case studies of these various factory estates would be useful to investigate, in addition to this research, to help establish a path toward urban farming and food security and a more ecologically restored environment.

When planning an urban farming system, types of food grown should meet the demands of health and environmental well-being and preferably a well-balanced local diet, keeping in mind the variety of nutrients and micronutrients found in the food.

Some suggested food to grow in the Klang Valley are common vegetable dishes in Malaysian cuisine, for example, 'Kangkong' (water spinach/Ipomoea Aquatica), "bokchoi" (brassica Rapa), loose-leaf, romaine and butterhead, and broccoli (Brassica oleracea). These are typically high in nutrition and easy to cultivate by anyone with little or no skill. Additionally, fish can be farmed using an aquaponics setup (a setup that involves the plants and fish in a shared system). Types of fish suitable for aquaponics setups may include Hoven's carp, empurau, catfish, "patin" fish, and sultan fish. It is important to note that non-native species of fish should not be encouraged to be farmed as they may find their way into water bodies and disrupt ecosystems elsewhere. In rural areas of Malaysia where popular restaurants are located, these urban farming techniques often sustain the restaurant's food supply from meat to vegetables.

Where to start an urban farm? Preferably a farm-to-table location, for example, grown on a rooftop/backyard of the restaurant (as in rural areas) or in a centralised food growing and distribution system with proximity to the restaurants. These could be set up by the local community, restaurant workers, or nongovernment organisations (N.G.O.s.) Hence the food can be sustainably sourced to maintain a healthy ecosystem.

Other farming methods include small plot farming, hydroponics with the aid of nutrient solutions, and seed trays. These would be just some of the materials needed. New and emerging urban farming methods include robotic farming, where robots efficiently manage a small plot of land to optimise the growth of crops around the clock (controlled by an application on the phone). Indoor farming and vertical farming in very tight or space restrictive areas are also becoming viable options.

\subsection{Factor 1 Confidence}

Confidence is a complex construct linked to many items, one of which is subjective difficulty. According to a 'gaming' study done by Constant and Levieux [16] on dynamic difficulty, "players seem to be much more overconfident with difficulty adapted to their skills." However, an adjustment in difficulty impacts the players' confidence. This link between difficulty and its direct effect on boosting or lowering confidence can be operationalised in the context of urban farming.

According to Terano, Mohamed [17], who researched the adoption of agricultural practices by farmers used the theory of planned behavior to look into the attitude, subjective norms, perceived behavioral control, awareness, and knowledge related to sustainable development agriculture practices in their research. They concluded that attitude and perceived behavioral control, when positive, highly influenced the rate of adoption. Their study focused on what influenced farmers' perception of urban farming using references 
to perceived behavioral control. Perceived behavioral control is one's capacity to carry out the task. This capacity could encompass practical and tacit knowledge and skills as well as financial capacity. A high capacity to do something forms high confidence. Hence one of the reasons why confidence is the main factor $[18,19]$.

Another study by Ida Naziera, Rika [20] suggests that confidence contributes to "the ease of adopting urban farming." The other important aspect of confidence within capacity is time management, in that one can be confident in adopting something provided they think they have time for it [21].

Hypothesis 1 (H1). 'Confidence' factor is likely to positively affect adopting the idea of urban farming among urbanites in the Klang Valley.

\subsection{Factor 2 Societal}

Societal influence, better known as social influences, emphasises how much urban farming is promoted and how people within a social circle may perceive urban farming. How the visible choices exist [22] can also affect how people view and grasp the idea of adopting urban farming. Societal aspects of urban farming perception may rely on questions/items regarding community actions where validation is involved [23]. Societies and cultures differ in their ways of thinking and adopting ideas [24]. This study applies to Malaysian society and the residents of Klang Valley.

Hypothesis 2 (H2). 'Societal' factor is likely to positively affect adopting the idea of urban farming among urbanites in the Klang Valley.

\subsection{Factor 3 Pleasantness}

Pleasantness may describe how one perceives the overall outlook of an urban farm and its material infrastructure. It seeks to analyse what stimulates a positive response; whether the person views it as clean, wants it to be clean, or set up in a particular manner (e.g., wooden, rustic, metal, plastic, and various other materials that define the structure). It may also analyse if the person prefers it to smell a certain way. Pleasantness is essential in encouraging people to adopt the idea of urban farming. For example, studying food (a stimulant), pleasantness is measured by humans' sensual responses to sight, taste, and smell. A medical study was done that closely measured blood pressure, heart rate, and other peripheral physiological measures. However, for lack of better equipment and simplicity, items on pleasantness for the context of urban farming were created and measured using a 10 point scale in the questionnaire [25]. Furthermore, visual images of various urban farming setups were shown to the respondents to triangulate their responses with the pleasantness factor.

According to a study on urban quality of life, people seek pleasantness in urban lifestyle whether it's what they eat, what they do, or how they live. One of the reasons for shifting to an urban area from a less developed region at the end of the day is to seek a better and more pleasant life [26].

Hypothesis 3 (H3). 'Pleasantness' factor is likely to positively affect adopting the idea of urban farming among urbanites in the Klang Valley.

\subsection{Factor 4 Naturalness}

This factor is significant in the food and drink industry. Individuals are more likely/ willing to purchase food items labeled "natural" as they feel it is more beneficial and free from harmful synthetic substances [27]. Questions include comparisons operationalized to the context of urban farming and other measurements towards perceptions on the naturalness of urban farming [28].

When applied to urban farming, individuals would likely embrace the idea of adopting urban farming strongly because of naturalness. It is important to note that urban agriculture is not $100 \%$ natural as many synthetic materials build its structure (e.g., P.V.C. tubing). 
Specific forms of urban farming, such as hydroponics, use chemical fertilizers. In daily life, numerous items that are bought from a store are unnaturally treated to become bigger, grow quicker, and satisfy the needs of buyer society. Naturalness is indeed a matter of perception.

Hypothesis 4 (H4). 'Naturalness' factor is likely to positively affect adopting the idea of urban farming among urbanites in the Klang Valley.

\subsection{Adoption}

This context represents the idea of urban farming and to what extent people are willing to grasp it. Adoption is influenced by the four factors previously discussed. However, by itself, it is also measured based on the following circumstances in a rather abstract way. The respondent is assumed to have been allowed to adopt urban farming, asked to judge the necessity and future intentions on the subject matter, and lastly, their overall interest in learning more. These measurements are based on the theory of planned behavior from items in other journals operationalized for the context of this study [29]. For all items, see (Table 1).

Table 1. Items and Variables Table. (Author's own).

\begin{tabular}{|c|c|c|}
\hline Factor & Item/Indicators & Source \\
\hline CF1 & "I don't think it's difficult to start doing urban farming" & {$[16,29]$} \\
\hline CF2 & "I am sure that I will be able to understand how to do urban farming" & {$[16,29]$} \\
\hline CF3 & "I am confident I can commit to doing at least some urban farming every day." & {$[16,29]$} \\
\hline CF4 & "Regardless of the method/setup of urban farming I think I would be able to do it." & {$[16,29]$} \\
\hline CF5 & "Physically I am confident to do urban farming" & {$[16,29]$} \\
\hline EF6 & $\begin{array}{l}\text { "I am confident that financially it won't be a problem when it comes to } \\
\text { uban farming" }\end{array}$ & {$[16,29]$} \\
\hline SC1 & "I live in a community where urban farming is well promoted" & [22] \\
\hline SC2 & $\begin{array}{l}\text { "I have family or friends that often educate / promote the concept of urban farming } \\
\text { to me." }\end{array}$ & {$[22]$} \\
\hline SE3 & $\begin{array}{l}\text { "I feel the sense of responsibility to start urban farming for the good of } \\
\text { my community" }\end{array}$ & {$[22]$} \\
\hline SC4 & "People in my community depend a lot on urban farms for their vegetables" & [22] \\
\hline SC5 & "My School/University shares knowledge on urban farming" & {$[22]$} \\
\hline SC6 & "It is common to see more shops selling urban farmed goods in my area" & {$[22]$} \\
\hline PL1 & "I think urban farming does not dirty my place" & {$[25,26]$} \\
\hline PL2 & "I don't think I will feel uncomfortable when doing urban farming" & {$[25,26]$} \\
\hline PL3 & "I don't think urban farming will cause any bad smells" & {$[25,26]$} \\
\hline PL4 & "I wouldn't be bothered by any bugs or insects when doing urban farming" & {$[25,26]$} \\
\hline PL5 & "I think Urban farming would make my surroundings more pleasing" & {$[25,26]$} \\
\hline PL6 & "I think urban farming will make me feel relaxed." & {$[25,26]$} \\
\hline NT1 & $\begin{array}{l}\text { "I think urban farmed vegetables are more natural compared to traditionally } \\
\text { farmed vegetables" }\end{array}$ & [28] \\
\hline NT2 & $\begin{array}{l}\text { "I think that methods of urban farming are more natural than methods of } \\
\text { traditional farming" }\end{array}$ & {$[28]$} \\
\hline NT3 & $\begin{array}{l}\text { "I think I can get more nutrients from urban farmed vegetables than traditional } \\
\text { farmed vegetables" }\end{array}$ & [28] \\
\hline NT4 & $\begin{array}{l}\text { "I think urban farmed vegetables are more healthy than traditional } \\
\text { farmed vegetables" }\end{array}$ & {$[28]$} \\
\hline AD1 & "I think I am likely to start doing urban farming in the near future." & [29] \\
\hline
\end{tabular}


Table 1. Cont.

\begin{tabular}{llc}
\hline Factor & \multicolumn{1}{c}{ Item/Indicators } & Source \\
\hline AD2 & "Given the opportunity I would experiment with urban farming." & {$[29]$} \\
\hline AD3 & "In my view I see urban farming as a necessity to practice" & {$[29]$} \\
\hline AD4 & "I think I will intentionally learn more about urban farming" & {$[29]$} \\
\hline
\end{tabular}

The strikethrough represents items/indicators that didn't meet the validity threshold.

\subsection{Relevant Past Studies and Research Gaps}

Over the course of 6000 years, to date, cities and various urban areas have been known to humans as hubs of trade and vast habitual developments. The concept ingrained in the minds of people have not changed. Although urban farming has slowly crept in during more recent decades, it will not take off until a profound societal change is initiated. Farmers for a significant number of years, visited cities to sell their produce. In today's society, the concept of a city being an area of farming has not penetrated people's minds [30]. In the advent of the sustainability crises that face our world today, many studies are being carried out to study consumer behavioral patterns. One theory most used and widely recognised is the social practice theory. Social practice theory focuses on circular economic solutions, especially for people in urban areas, and other studies suggest that social practice is shifting its focus on more environmental concerning behaviors [31].

There aren't many studies on urban farming in Malaysia, but a few known studies will be discussed here. A study by a Malaysian group of researchers suggests several helpful factors influence people's incentive to practice urban farming. To name a few, confidence and society have a positive perception that affects people's ability to practice urban farming [20]. Other studies suggest transitions and possible approaches that make urban farming a suitable alternative, considering laws, regulations, and types of food to be grown, and even providing examples of alternative high protein sources such as crickets [32].

Another local study showed people's importance related to community farming was for environmental, social, economic, and healthy lifestyles reasons [33]. This study was done among people who primarily indulged in urban agriculture, and hence this was their perspective. Our study focuses on gaining the perspective of people who have not done urban farming before.

A foreign study in Italy suggested people's perceptions and acceptance of the idea of adopting urban farming were quite impressive, as most people lived in houses with rooftops and rooftop farming was highly encouraged. They also displayed a high preference for urban-farmed goods here [34]. All these studies showed an interesting perspective, and perhaps a comparative study in the future may help us better comprehend people's overall perceptions.

\section{Materials and Methods}

Displayed below in Figure 1 is a rendition of the framework used. In the structure, four independent factors (societal, confidence, pleasantness, and naturalness) impact the idea of adoption and various perceptions of urban farming by urbanites. Studies have indicated that the accompanying independent factors can affect individuals' perceptions of adoption. For this study, we analysed the effects of shown variables and their impact on adoption due to their relevance with urban farming.

\subsection{Research Scope and Sampling Plan}

According to the G-Power index, a sample of at least 129 is good enough for the number of target variables. The sample data collection took on a snowball-like approach where people in the Klang Valley sent it out to people they knew, and so forth, to cover the threshold of respondents needed. Specific questions had been put in to regulate 
who responded. The research scope was only within the Klang Valley of Malaysia and its residents.

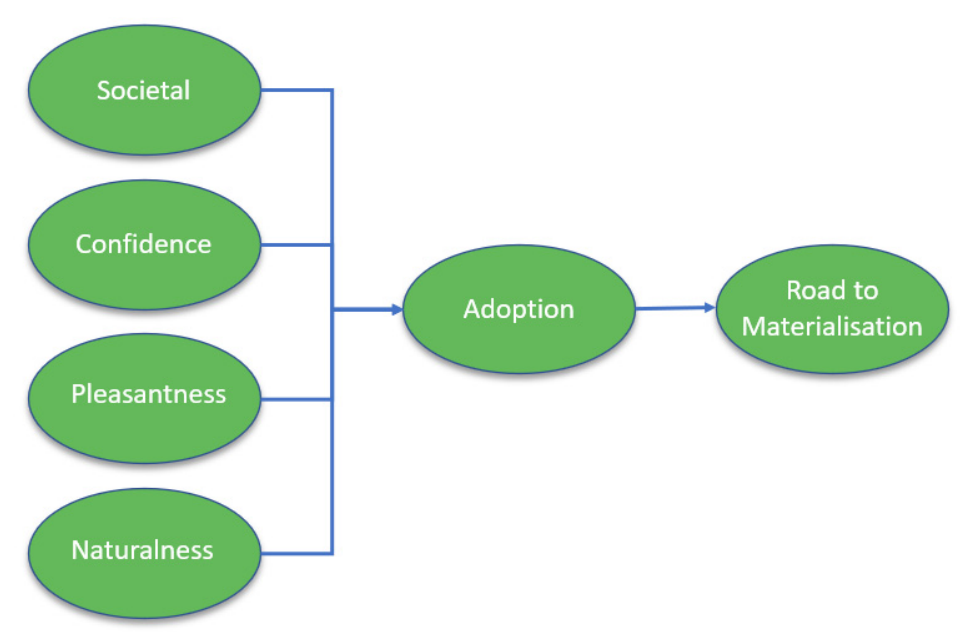

Figure 1. Conceptual Framework. (Authors' own).

\subsection{Research Approach \& Design}

The study primarily took a quantitative approach to gather data to analyse people's perceptions of urban farming. It was done using carefully selected factors/variables that each contained several items used to measure those variables. Ultimately the impact of each variable on adoption was calculated. The research additionally gathered qualitative data to triangulate the results of the quantitative data. The qualitative study presented two crucial, open-ended questions to the respondents, and the findings were then categorised and coded thematically. Both sets of data were gathered from a single online survey using Google Forms. The research was initially designed to be done via face-to-face interviews, but due to a number of unforeseen events (e.g., COVID 19), the survey was rendered redundant and remade to suit an online audience with a more simplistic, yet in-depth, approach that was quickly completed in $10 \mathrm{~min}$ or under.

Furthermore, the same survey collected imagery and demographic information, which created a clearer picture of what people perceive about urban farming visually, where they prefer to do it, and how much they generally understood urban farming. The questionnaire started with a briefing of the study and a few short yes-no questions for eligibility. This was followed by the first section, which consisted of 'warm-up' questions on how much they generally knew about urban farming, and one open-ended question.

After this came the items for each of the factors and their respected sections. The factors in the SPSS software were labeled as CF (Confidence), SC (Societal) PL (Pleasantness) NT (Naturalness) AD (Adoption). With the factors section finished, the respondents arrived at the visual section. The purpose of this section was to see what type of urban farming setup seemed visually pleasing to them. They reviewed ten high-quality pictures before moving to the final selections. The final section included basic demographic questions, one more open-ended question, and the last question on where they would prefer to do urban farming given an opportunity (outdoors or indoors or both).

\subsection{Data Analysis}

The analysis was mapped into four sections and performed using the latest SPSS software. The sections were data cleaning, respondent demographics, descriptive analysis, and hypothesis testing. For data cleaning, variance analysis (straight line error) was performed on all the scale questions; some unfavorable data was deleted. When the data was cleaned, 133 responses were left. These were then analysed. Three data validity tests were performed on the scale questions using factor analysis. The options selected for the analysis were for statistics, initial solutions, for the correlation matrix, coefficients, 
significant levels, determinants, and K.M.O. and Bartletts test of sphericity. In the Extraction tab, " 5 " fixed number of factors were selected. For the rotation tab, 'varimax' was chosen. The options tab coefficient display format was made to suppress small coefficients with an absolute value below 0.4 . The validity test was allowed to run. In the first validity test, K.M.O. and Bartlett's test of sphericity, the sampling adequacy was around $79 \%$, passing the threshold of $60 \%$. In the second test, the total variance explained test (T.V.E.) cumulative was around $62.5 \%$ greater than the threshold of $50 \%$. In the third test, the rotated component matrix, the factor loading results showed the majority of questions/items had relevant factors with loadings above 0.6 . Those that did not meet the criteria were disregarded from the other analysis. With this, a successful validity test was concluded.

The next test involved a reliability analysis factor by factor. The trial excluded the questions/items in each factor that did not meet the validity test threshold from the previous tests. Bootstrapping was carried out and, for all the factors, the Cronbach alpha was above 0.8 , which successfully concluded this test. After that, a normality test was done, with histograms, normality plots, and stem leaf diagram to conclude all angles. The test showed that skewness and kurtosis were within the limits of -1 and +1 ; furthermore, all the diagrams appeared to be satisfactory.

In the descriptive analysis procedure, a correlation table was generated. Further information on the results and objectives/hypothesis was presented with respective diagrams in the findings section. Demographic data are also presented in the report findings section.

\subsection{Research Instruments}

The research instruments were taken from previous studies for measuring Adoption. Some were constructed based on information from various psychological studies in the literature review. All items for each factor were operationalised for the context of urban farming (Table 1).

\section{Results}

\subsection{Straight Line and Validity Tests}

To determine if people did not genuinely answer the survey, a straight-line test (Variance Analysis) was conducted using the results keyed into SPSS. Out of the survey of $\mathrm{n}=135$, two respondents had straight line errors and were deleted, leaving the total number as $\mathrm{n}=133$. For the validity test for all five factors (confidence, societal, pleasantness, naturalness, and the dependent variable Adoption), the K.M.O. and Bartlett's Test, K.M.O. measure of sampling adequacy shown in Table 2. was well above the threshold of 0.60 at 0.792 (indicated in red). Hence this test was passed.

Table 2. K.M.O. \& Bartlett's Test. (Author's own).

\begin{tabular}{ccc}
\hline Kaiser-Meyer-Olkin Measure of Sampling Adequacy. & 0.792 \\
\cline { 2 - 3 } $\begin{array}{c}\text { Bartlett's Test of } \\
\text { Sphericity }\end{array}$ & Approx. Chi-Square & 1971.057 \\
\cline { 2 - 3 } & Sig. & 325 \\
\hline
\end{tabular}

\subsection{Total Variance Explained (T.V.E.)}

T.V.E test for validity was a pass. The threshold was at $50 \%$, and the test for factors was at $62.570 \%$, as shown in Table 3 (indicated in red).

The last test for Validity, the Rotated Component Matrix Test (Table 4 Below), was also a success. Any values above 0.5 and within the columns were accepted. However, a few questions had to be excluded, such as CF6 (see Tables 1 and 4), which was below the bare minimum threshold of 0.5 at $<0.40$, this value was too low and insignificant. SC3 with a value of 0.605 (see Tables 1 and 4) did not align within the same column as its peers. Hence it was rejected. PL6 with a value of 0.445 (see Tables 1 and 4) was also below 0.5 and dismissed. 
Table 3. Total Variance Explained. (Author's own).

\begin{tabular}{|c|c|c|c|c|c|c|c|c|c|}
\hline \multirow[b]{2}{*}{ Component } & \multicolumn{3}{|c|}{ Initial Eigenvalues } & \multicolumn{3}{|c|}{ Extraction Sums of Squared Loadings } & \multicolumn{3}{|c|}{ Rotation Sums of Squared Loadings } \\
\hline & Total & $\begin{array}{c}\% \text { of } \\
\text { Variance }\end{array}$ & $\begin{array}{c}\text { Cumulative } \\
\%\end{array}$ & Total & $\%$ Variance & $\underset{\%}{\text { Cumulative }}$ & Total & $\%$ Variance & $\underset{\%}{\text { Cumulative }}$ \\
\hline 1 & 7.394 & 28.438 & 28.438 & 7.394 & 28.438 & 28.438 & 3.751 & 14.426 & 14.426 \\
\hline 2 & 3.140 & 12.078 & 40.516 & 3.140 & 12.078 & 40.516 & 3.333 & 12.821 & 27.247 \\
\hline 3 & 2.371 & 9.120 & 49.636 & 2.371 & 9.120 & 49.636 & 3.251 & 12.503 & 39.750 \\
\hline 4 & 1.858 & 7.147 & 56.783 & 1.858 & 7.147 & 56.783 & 2.982 & 11.469 & 51.219 \\
\hline 5 & 1.505 & 5.787 & 62.570 & 1.505 & 5.787 & 62.570 & 2.951 & 11.352 & 62.570 \\
\hline
\end{tabular}

Table 4. Rotated Component Matrix Test. (Author's own).

\begin{tabular}{|c|c|c|c|c|c|}
\hline \multicolumn{6}{|c|}{ Rotated Componenet Matrix } \\
\hline & \multicolumn{5}{|c|}{ Component } \\
\hline & 1 & 2 & 3 & 4 & 5 \\
\hline Section A Q1 & & & 0.685 & & \\
\hline Section A Q2 & 0.403 & & 0.690 & & \\
\hline Section A Q3 & & & 0.756 & & \\
\hline Section A Q4 & & & 0.746 & & \\
\hline Section A Q5 & & & 0.786 & & \\
\hline Section A Q6 & & & Value too low & & \\
\hline Section B Q1 & & & & 0.755 & \\
\hline Section B Q2 & & & & 0.505 & \\
\hline Section B Q3 & 0.605 & & & & \\
\hline Section B Q4 & & & & 0.795 & \\
\hline Section B Q5 & & & & 0.631 & \\
\hline Section B Q6 & & & & 0.818 & \\
\hline Section C Q1 & & & & & 0.747 \\
\hline Section C Q2 & & & & & 0.668 \\
\hline Section C Q3 & & & & & 0.783 \\
\hline Section C Q4 & & & & & 0.553 \\
\hline Section C Q5 & & & & & 0.625 \\
\hline Section C Q6 & 0.415 & & & & 0.445 \\
\hline Section D Q1 & & 0.881 & & & \\
\hline Section D Q2 & & 0.830 & & & \\
\hline Section D Q3 & & 0.833 & & & \\
\hline Section D Q4 & & 0.916 & & & \\
\hline Adoption Q1 & 0.760 & & & & \\
\hline Adoption Q2 & 0.837 & & & & \\
\hline Adoption Q3 & 0.746 & & & & \\
\hline Adoption Q4 & 0.768 & & & & \\
\hline
\end{tabular}

Extraction Method: Principal Component Analysis. Rotation Method: Varimax with Kaiser Normalization. Rotation converged in 6 iterations. Note that each section and their questions directly reflect Table 1.

Financial questions such as CF6 (see Tables 1 and 4) could not find their place among their peers. One observation was that the nature of the question demanded measurement of confidence in financial capabilities related to urban farming. This distinction was not clear to people. Possibly, no one was sure what the costs of setting up an urban farm might be in the first place and whether or not it would be cheap or expensive. SC3's (see Tables 1 and 4 ) observation for exclusion was not fitting. This is because the question demanded self-reflection after a few questions about other people the respondent had judged. For PL6 (see Tables 1 and 4) it is unclear why it fell below the threshold of 0.5. However, one explanation could be that it demanded deeper self-reflection, and people could not gauge how relaxed urban farming would make them. After all, respondents interviewed had no urban farming experience, so the item was unclear. 


\subsection{Reliability and Outliers Test}

Reliability test $1-$ Cronbach Alpha for all five factors exceeded the 0.70 thresholds at 0.837 . Hence the data collected was reliable according to this test. Reliability test $2-$ Normality Test. All Skewness and Kurtosis for all the variables were between -1 and +1 hence this passed the first reliability test for normality. Although there were some outliers seen in societal, pleasantness and naturalness, they were not removed as there was no need because the results were tested to be normal.

\section{Findings \& Discussion}

The study had fairly balanced respondents in terms of gender (male and female), with 62 males and 69 females and two people not stating, with a total of 133 respondents. The age group of the study was (18-24) $29.3 \%$, (25-39) $33.1 \%$, (40-60) $27.8 \%$, (60 plus) $9.8 \%$. Some things to note from the sample taken on how much respondents generally knew about urban farming are that $21.6 \%$ of the people in the sample had not heard about urban farming before taking the survey, while $78.4 \%$ had. Nearly half $(44.3 \%)$ of the respondents had not heard about aquaponics before taking the survey, but the rest had. Where hydroponics is concerned, $70 \%$ of the respondents had heard about it before taking the survey, while the rest had not.

In summary, these data suggest that roughly among the respondents, more people had heard about hydroponics than aquaponics. More than $75 \%$ of the respondents in this survey had heard about urban farming before taking this survey. With respect to the preferred location to do urban farming, most people (56\%) wouldn't mind doing it indoors and outdoors, while a significant proportion preferred outdoors only (34.3\%), and the rest, a mere $9.6 \%$, preferred indoors only.

These descriptive results in Table 5 . show how the respondents perceived the following factors about urban farming. Among the results, societal was the lowest (indicated in red). Hence what people felt about the societal aspect pertaining to urban farming was weak. A study by Ngahdiman, Terano [17] reported that "Societal influences such as family, friends, and others such as government, public figures, and environmentalists play important roles in creating positive perception towards urban agriculture among urban dwellers." While their report is significant, when compared to other factors such as confidence, naturalness, and pleasantness, societal was the weakest. However, this should not be disregarded. As a result, the presence of urban farming/promotion/ dependence is generally ineffective. This adds a new contribution to the knowledge base from a different angle (based on items this study used, seen in Table 1).

Table 5. Descriptive Statistics: mean and standards deviation. (Author's own).

\begin{tabular}{cccccc}
\hline & N & Minimum & Maximum & Mean & Std. Deviation \\
\hline CF & 133 & 2.00 & 10.00 & 6.5489 & 1.72796 \\
SC & 133 & 0.00 & 10.00 & 3.4180 & 1.96615 \\
PL & 133 & 1.00 & 10.00 & 6.1985 & 1.73284 \\
NT & 133 & 0.00 & 10.00 & 6.3496 & 2.29045 \\
AD & 133 & 1.25 & 10.00 & 6.4004 & 2.00070 \\
Valid N (listwise) & 133 & & & & \\
\hline
\end{tabular}

CF-Confidence; SC—Societal; PL—Pleasantness; AD—Adoption.

The probability value for significance was $<0.05$. Hence, all the hypotheses were accepted. All hypotheses were related to positive impact and were relevant to adopting the idea of urban farming, but which had the most relevance and impact among the four, and by approximately how much? A correlation only shows the relation between two variables; therefore, a coefficient test was adopted with factors showing one on one results (e.g., confidence against adoption, pleasantness against adoption, etc.). Confidence and pleasantness against adoption had a higher impact than the 'societal' aspect and 'naturalness' aspect against adoption by themselves (Table 6, numbers $0.525 \& 0.450$ ). 
However, a better way to analyse this would be by putting all the variables together (in a stimulated scenario) and observing which factors most influence an urbanite living in the Klang Valley concerning adopting the idea of urban farming.

Table 6. Correlation test. (Author's own).

\begin{tabular}{cccccc}
\hline & AD & CF & SC & PL & NT \\
\hline $\begin{array}{c}\text { Pearson } \\
\text { Correlation }\end{array}$ & 1.000 & 0.525 & 0.241 & 0.450 & 0.218 \\
AD & & & & & \\
CF & 0.525 & 1.000 & 0.267 & 0.317 & 0.111 \\
SC & 0.241 & 0.267 & 1.000 & 0.307 & 0.234 \\
PL & 0.450 & 0.317 & 0.307 & 1.000 & 0.318 \\
NT & 0.218 & 0.111 & 0.234 & 0.318 & 1.000 \\
Sig. (1-tailed) & - & 0.000 & 0.003 & 0.000 & 0.006 \\
AD & & - & 0.001 & 0.000 & 0.103 \\
CF & 0.000 & 0.001 & - & 0.000 & 0.003 \\
SC & 0.003 & 0.000 & 0.000 & - & 0.000 \\
PL & 0.000 & 0.103 & 0.003 & 0.000 & - \\
NT & 0.006 & & & & \\
\hline
\end{tabular}

The most relevant factors contributing to adopting the idea of urban farming were confidence and pleasantness, as indicated in red in the coefficient table (Table 7 below). The difference between the correlations test and coefficients test is that in the correlations test, each variable's impact on adoption was measured solely one on one. However, in the coefficients test, all variables were run together in multiple scenarios, and the impact of each on adoption was dampened by the other. In both tests, it is clear the impact confidence and pleasantness had on adoption. This answers the aim of the research, which is 'how relevant each of the factors of confidence, societal, pleasantness, and naturalness, are towards adopting the idea of urban farming'. This translates to advice where if one were to set up, for example, a campaign to try and get people to adopt the idea of urban farming, one should focus on taking advantage of the already strong confidence in Klang Valley urbanites. Pleasantness should also be integrated by deciding how to make urban farming a more 'pleasant experience' through its practicality, look (design/color), and odour. These two factors strongly reflect the practice theory and suggest that older material infrastructures, practical/tacit knowledge/skills, and common understandings must be replaced to encourage new practices.

Table 7. Coefficient test dependent variable AD. (Author's own).

\begin{tabular}{|c|c|c|c|c|c|c|c|}
\hline \multirow{2}{*}{ Model } & \multicolumn{2}{|c|}{$\begin{array}{l}\text { Unstandardized } \\
\text { Coefficients }\end{array}$} & \multirow{2}{*}{$\begin{array}{c}\text { Standardized } \\
\text { Coefficients } \\
\text { Beta }\end{array}$} & \multirow{2}{*}{$\mathbf{t}$} & \multirow{2}{*}{ Sig. } & \multicolumn{2}{|c|}{ Collinerarity Statistics } \\
\hline & B & Std. Error & & & & Tolerance & VIF \\
\hline $\begin{array}{c}1 \\
\text { (Constant) }\end{array}$ & 0.675 & 0.695 & & 0.927 & 0.333 & & \\
\hline $\mathrm{CF}$ & 0.486 & 0.087 & 0.419 & 5.573 & 0.000 & 0.868 & 1.152 \\
\hline SC & 0.024 & 0.077 & 0.024 & 0.314 & 0.754 & 0.854 & 1.172 \\
\hline PL & 0.330 & 0.091 & 0.285 & 3.615 & 0.000 & 0.789 & 1.268 \\
\hline NT & 0.066 & 0.065 & 0.076 & 1.009 & 0.315 & 0.878 & 1.139 \\
\hline
\end{tabular}

R-Squared is a statistical measure of fit that indicates how much variation of a dependent variable is defined by the corresponding independent variables. R-squared is the "percentage of variance explained" by the model. It is calculated as a fraction by which the variance of the errors is less than the variance of the dependent variable using Cohen's Test via SPSS. The following results were observed. R-squared was 37.1\% (Table 8 indicated in red) and represents prediction strength. If R-squared is $>32 \%$ it is usually considered to have a 'high impact' on the dependent variable (adoption), as this is a study 
in social sciences. 'High impact' refers to a scenario where if all four variables, confidence, pleasantness, naturalness, and societal, are in play as perceived by the respondents, the variables would strongly influence their adoption of the idea of urban farming.

Table 8. Model Summary for dependent variable AD (R Square). (Author's own).

\begin{tabular}{cccccc}
\hline Model & R & R Square & Adjusted R Square & Std. Error of the Estimate & Durbin-Watson \\
\hline 1 & 0.609 & 0.371 & 0.351 & 1.61187 & 1.971 \\
\hline \multicolumn{5}{c}{ a. Predictors: (Constant), NT, CF, SC, PL } \\
\hline
\end{tabular}

\section{Small Scale Qualitative Study (Additional Findings/Recommendations)}

A qualitative study was done, and the questions asked were: “Urban farming is becoming more important as populations worldwide increase. What do you think of this sentence?" "In 1-5 words, say what will encourage you to do urban farming". The objective here was to tap further into a perception of urban farming among the respondents to seek people's positive outcomes and practical constraints in adopting the idea of urban farming. The qualitative study concluded with the following diagram after manual thematic coding and categorization (Table 9).

Table 9. Qualitative Findings Thematically Categorised. (Author's own).

\begin{tabular}{cc}
\hline Positive Outcomes & Practical Constraints/Challenges \\
\hline Health & Space \\
Self Sufficiency & Time \\
Food Security & Supply Chain \\
Self-Awareness & Tools \& resources \\
Economic Benefit & Community/Government Support \\
Popularity & \\
\hline
\end{tabular}

The key findings in this article for urbanites living in the Klang Valley are that when confidence increases together with pleasantness, the idea of adoption is stronger. In addition, together with naturalness and societal the impact is significant. Furthermore, this study's qualitative findings show that while there were positive outcomes to complement the quantitative research, practical constraints were also highlighted. These constraints are space, time, supply chain, resources, tools, community and government support.

From the context of the answers, space describes the lack of household or community land for urban farming activities. As a solution, the promotion of vertical farming techniques can mitigate this issue. The proper training and promotion of such unique farming techniques could be the focus of educational institutes, government-sponsored programs, and manufacturers of such products (vertical farming setups). Regulators, especially in the housing area, should consider policies for housing design with an urban farming space or communities allocated land for urban farming.

Governments and retailers can take initiatives to source urban farming materials and make them more commonplace in society (anything from starter kits for hydroponics to materials, D.Y.I. urban farming, and guides). A strong supply chain for tools and materials should be created. Having these kits sold in online and physical stores is another progressive step. Once again, though they may be already present in some stores, their promotion is vital, and more work should be done to step up the marketing of such products.

People say they don't have time. Social practice shows that the activities people are used to every day take up time, creating a sense of 'not having time' for other activities. Upon further promoting an urban farming lifestyle specifically within view of a community, it could incentivise people to forgo certain activities to make time for other things. For example, an N.G.O. could set up urban farms in a park where people would usually exercise or relax. Instead of using the time for the latter, people can see others interacting with the urban farm and be incentivised to join it; this is societal influence. To make it 
better, the set up should be neat, new, and pleasant to the eyes of the urbanites, and those responsible for setting it up should encourage people to try their hand in it (to boost their confidence).

Another example could be encouraging more restaurants to grow their food (ingredients), with N.G.O.s willing to set up urban farms for restaurants and provide advice and training. This may require restaurants to invest an amount for this service initially. If done with proper planning, the benefits of the harvest (vegetables/fish.) should outweigh that of time and money needed to buy ingredients elsewhere at higher prices. This may change the social practice on a commercial basis.

Below are the top three most liked images from ten pictures in the survey. They are ranked from first to third. The ranking is based on the average of the scores (noted out of 10). They show people's preference of urban farming set-ups they prefer and are to their liking.

Figure $2 b$ shows a typical DIY urban farming setup for personal use. Such a setup does not require much expertise to use. The structure is surrounded by plants that emphasise the pleasantness of greenery in an urban farming setting. Figure 2a shows an office building with various plants growing from the sidewalls. Such an image portrays a potential urban farming setup where the structure of buildings could be used to grow food. Figure $2 \mathrm{c}$ shows a neatly kept rooftop urban farm with a community of people surrounding it. Such an image portrays a sense of community and practical rooftop space for urban farming.

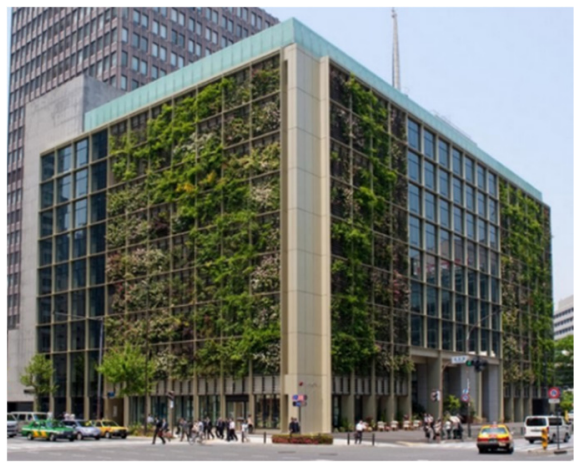

(a)

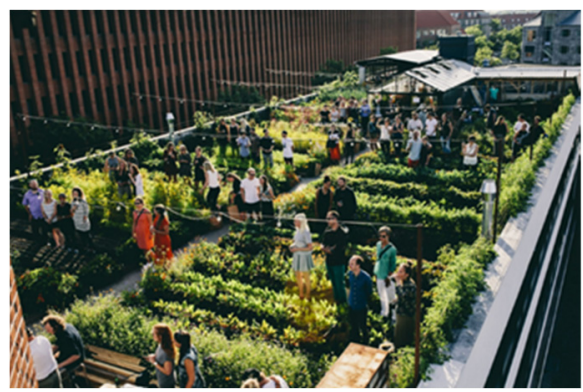

(c)

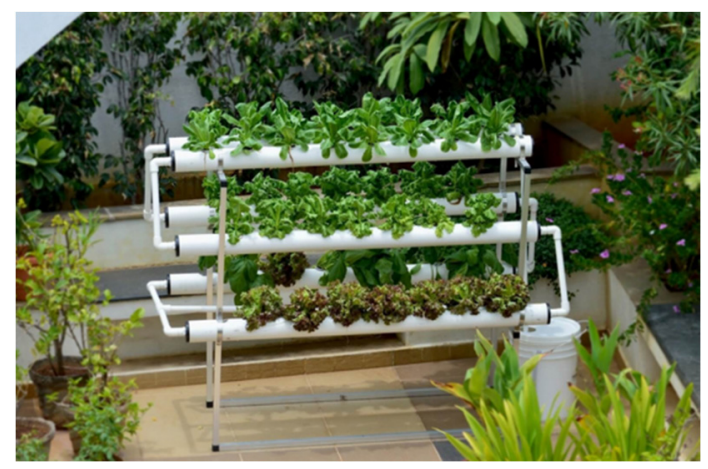

(b)

Figure 2. Images depicting urban farming (a) 2nd (8.34/10). (b) 1st (8.44/10). (c) 3rd (8.24/10).

Only three out of the ten images used in the questionnaire are shown in this article. Each picture had different setups for urban farming. Each setup was diverse. Some showed people working in the urban farm. Some depicted a smelly scene. Some showed wild growth of plants in a larger space and within a more confined space. These were done to study how visual setups stimulate the senses to gauge pleasantness. Out of ten pictures, the top three photos with the highest average of positive feedback are shown above. It is quite clear that pictures emphasising neat-looking material infrastructure were preferred to others. The sense of community/societal was not completely neglected, as the respondents 
appreciated a photo with a community walking around an urban farm (Figure 2c) but rated slightly lower another photo of a community working in the urban farm (not shown).

The naturalness aspect was observed as respondents were satisfied with the images with the most natural greenery per image area compared to other images. One of the images (not shown here) was a cricket farm ( $0 \%$ greenery) comprised mainly of crickets in cages, this was greatly disliked. This further emphasis the importance of pleasantness in terms of appeal, and smell and taste. This hints that there may be a lack of acceptance toward the food (crickets).

Figure $2 \mathrm{a}$, an office building with plants growing on its side, may adhere to satisfying the space constraint respondents constantly referred to. It also compliments the pleasantness factor in the eyes of the urbanite. The image also shows that people don't mind seeing buildings covered in greenery. Apartment management and offices can set up more buildings with greenery on them focusing on urban farming. For this, policies need to be in place that more specifically dictate what should encompass the allocated space for "greenery" in an infrastructural setting. This ties in with government support and the space dilemma, and what plants can be grown safely and easily in such settings.

Many startups are presenting direct options to people when it comes to their food practices. There are vending machines for fresh lettuce restocked every few days in businesses. Certain offices in foreign countries such as Japan have indoor urban farms growing tomatoes in meeting rooms and big crops (such as wheat) on the ground floors. This natural atmosphere is an attempt to change what a 'normal' office is like concerning the visual, olfactory, and other senses. Newer buildings should strongly emphasis integrating greater ability to produce food, creating a pleasing environment for employees and bringing about a stronger connection with nature that is all but gone in most big cities.

Figure $2 b$ (which was the most highly rated) further strengthens people's desires for tools and resources. People like the idea of such a setup. It is a basic setup for urban farming that anybody with little or no knowledge can learn to set up. However, availability and promotion of such 'DIY' equipment should be more emphasised. All in all, there was a degree of contrast to what seemed pleasing and neat visually.

The behavioural patterns observed in the study are related to the social sciences, given that aspects of included personal confidence, human interaction, and involvement of social practice theory in the adoption of urban farming. However, when broken down further, elements of decision science and health science were observed. Personal decisions (based on time, space, tools and resources available), regulatory elements, and processes (government support, supply chain) all make up the decision science aspect in calls for action to be addressed in these areas. Health sciences are concerned, in that pleasantness plays a great deal in incentivising the adoption of urban farming and setting people's minds at ease. In addition, the current state of food security in Malaysia, nutrition in terms of the food farmed, and recommended foods to grow all are related to the health sciences.

\section{Conclusions}

In conclusion, any campaign focused on enabling people to grasp the initial idea of adopting urban farming should focus on building upon their already strong confidence in carrying out doing urban farming. Pleasantness should be well orchestrated in the design of various urban farms, with considerations on how they may look. Besides these two factors, the other two, naturalness and societal, should be included to allow people to grasp the idea of urban farming.

Naturalness has an effect as well, although not so significant; hence hydroponics, which uses chemical fertilisers, is sometimes is still acceptable by people. The whole set-up of urban farms, which use pipes and plastic materials, may also be acceptable. Finally, societal influence may create a positive image of urban farming, but a greater presence of urban farming in a society will not necessarily lead to people adopting the idea of urban farming in the short term. Space, time, supply chain, resources, tools, community and government support are some constraints, and ways to tackle each are discussed above. 


\section{Future studies/Limitations}

1. Interview more people in the business of urban farming, obtain their opinions and how they adopted and materialised urban farming practices for society.

2. Obtain perceptions of urban farming from policymakers/landholders (i.e., community urban farm owners).

3. Similar studies in more rural areas are also encouraged, where the Orang Asli live to obtain their perceptions.

4. This study is limited to one region. Therefore, comparative studies with different countries or regions are recommended to obtain a better idea of diversity among social thinking and practices.

5. More factors could be studied with more items to strengthen the findings.

6. Conduct comparative case studies into local and foreign factory estates, eco restoration measures and urban farming implementation.

Author Contributions: Conceptualization, L.I. and B.V.A.; data curation, L.I.; formal analysis, D.F.A. and B.V.A.; funding acquisition, G.-O.T.; investigation, D.F.A. and B.V.A.; methodology, D.F.A.; project administration, L.I.; resources, D.F.A., B.V.A., G.-O.T. and L.I.; software, D.F.A. and B.V.A.; supervision, L.I.; validation, B.V.A.; writing-original draft, D.F.A.; writing-review and editing, G.-O.T. All authors have read and agreed to the published version of the manuscript.

Funding: This work was supported by research grants entitled "Increasing the institutional capacity in the field of research at the Politehnica University of Timişoara 3C-UPT CNFIS-FDI-2021-0573", project director prof. eng. Radu-Emil Precup, Ph.D.

Institutional Review Board Statement: Not applicable.

Informed Consent Statement: Not applicable.

Data Availability Statement: The data of current study can be obtained from corresponding author.

Conflicts of Interest: The authors declare no conflict of interest.

\section{References}

1. United Nations, Department of Economic and Social Affairs, Population Division. World Population Prospects 2019: Highlights; ST/ESA/SER.A/423; United Nations: NewYork, NY, USA, 2019.

2. Sulaiman, N.; Yeatman, H.; Russell, J.; Law, L.S. A Food Insecurity Systematic Review: Experience from Malaysia. Nutrients 2021, 13, 945. [CrossRef] [PubMed]

3. Napolitano, G. Stop the Waste: UN Food Agencies Call for Action to Reduce Global Hunger. Economic Development 2019. Available online: https:/ / news.un.org/en/story/2019/10/1049181 (accessed on 20 March 2020).

4. Rezaei, M.; Liu, B. Food Loss and Waste in the Food Supply Chain; International Nut and Dried Fruit Council: Reus, Spain, 2017; pp. 26-27.

5. Florida, R.; Fasche, M. The Rise of the Urban Creative Class in Southeast Asia; Martin Prosperity Insitute: Toronto, ON, Canada, 2017; p. 58 .

6. Jennings, S.; Cottee, J.; Curtis, T.; Miller, S. Food in an Urbanized World. The Role of City Region Food Systems in Resilience and Sustainable Development; FAO: Oxford, UK, 2015.

7. Nafisi, N.; Tahir, O.; Nafisi, S.; Ishak, N. Effectiveness of urban farming program in providing multiple benefits to the urban community in Malaysia. J. Archit. Environ. Struct. Eng. Res. 2020. [CrossRef]

8. Gerber, P.J.; Steinfeld, H.; Henderson, B.; Mottet, A.; Opio, C.; Dijkman, J.; Falcucci, A.; Tempio, G. Tackling Climate Change through Livestock-A Global Assessment of Emissions and Mitigation Opportunities; Food and Agriculture Organization of the United Nations (FAO): Rome, Italy, 2013.

9. Sharma, N.; Acharya, S.; Kumar, K.; Singh, N.; Chaurasia, O.P. Hydroponics as an advanced technique for vegetableproduction: An overview. J. Soil Water Conserv. 2018, 17, 364-371. [CrossRef]

10. Jalava, M.; Kummu, M.; Porkka, M.; Siebert, S.; Varis, O. Diet Change-A solution to reduce water use. Environ. Res. Lett. 2014, 9 , 074016. [CrossRef]

11. Pandian, M.; Ahimaz, P. Nesting behaviour of the Baya weaver bird, Ploceus philippinus (Linnaeus)(Passeriformes: Ploceidae) in rural Tamil Nadu, India. Int. J. Ecol. Environ. Sci. 2018, 44, 33-42.

12. Shamsudin, N. Farming in the City. New Straits Times, 21 July 2017. Available online: https://www.nst.com.my/opinion/ columnists/2017/07/259309/farming-city (accessed on 2 June 2020). 
13. OEC. Malaysia (MYS) Exports, Imports, and Trade Partners. Available online: https://oec.world/en/profile/country/mys (accessed on 2 June 2020).

14. Spaargaren, G.; Lamers, M.; Weenink, D. Practice Theory and Research-Exploring the Dynamics of Social Life; Routledge: London, $\mathrm{UK}, 2016$. [CrossRef]

15. Strengers, Y.; Maller, C. Integrating health, housing and energy policies: Social practices of cooling. Build. Res. Inf. 2011, $39,1-15$. [CrossRef]

16. Constant, T.; Levieux, G. Dynamic Difficulty Adjustment Impact on Players' Confidence. In Proceedings of the 2019 CHI Conference on Human Factors in Computing Systems, Glasgow, UK, 4 May 2019; Association for Computing Machinery: New York, NY, USA, 2019; p. 463.

17. Terano, R.; Mohamed, Z.; Shamsudin, M.N.; Latif, I.A. Factors Influencing Intention to Adopt Sustainable Agriculture Practices among Paddy Farmers in Kada, Malaysia. Asian J. Agric. Res. 2015, 9, 268-275. [CrossRef]

18. Tiraieyari, N.; Karami, R.; Ricard, R.M.; Badsar, M. Influences on the Implementation of Community Urban Agriculture: Insights from Agricultural Professionals. Sustainability 2019, 11, 1422. [CrossRef]

19. Mohamed Haris, N.B.; Garrod, G.; Gkartzios, M.; Proctor, A. The Decision to Adopt Organic Practices in Malaysia; a Mix-method Approach. In Proceedings of the 92nd Annual Conference, Coventry, UK, 16-18 April 2018.

20. Ida Naziera, N.; Rika, T.; Zainalabidin, M.; Sharifuddin, J. Factors affecting urban dwellers to practice urban agriculture. Int. J. Adv. Res. 2017, 5, 1580-1587. [CrossRef]

21. Martin, F.; Stamper, B.; Flowers, C. Examining Student Perception of Readiness for Online Learning: Importance and Confidence. Online Learn. 2020, 24, 38-58. [CrossRef]

22. Book, L.A.; Tanford, S. Measuring Social Influence From Online Traveler Reviews. Int. J. Hosp. Tour. Insights 2019, 3, 54-72. [CrossRef]

23. Alamian, A.; Paradis, G. Individual and social determinants of multiple chronic disease behavioral risk factors among youth BMC Public Health 2012, 12, 224. [CrossRef] [PubMed]

24. Schwartz, S.H. Ethnographic Journeys to Cross-Cultural Research, Chapter: Causes of Culture: National Differences in Cultural Embeddedness; Hebrew University of Jerusalem: Jerusalem, Israel, 2009.

25. Kaneko, D.; Toet, A.; Brouwer, A.-M.; Kallen, V.; van Erp, J.B.F. Methods for Evaluating Emotions Evoked by Food Experiences: A Literature Review. Front. Psychol. 2018, 9, 911. [CrossRef] [PubMed]

26. D'Acci, L. Monetary, Subjective and Quantitative Approaches to Assess Urban Quality of Life and Pleasantness in Cities (Hedonic Price, Willingness-to-Pay, Positional Value, Life Satisfaction, Isobenefit Lines). Soc. Indic. Res. 2014, 115, 531-559. [CrossRef]

27. Araya, S.; Elberg, A.; Noton, C.; Schwartz, D. Identifying Food Labeling Effects on Consumer Behavior. SSRN Electron. J. 2018, 1. [CrossRef]

28. Román, S.; Sánchez-Siles, L.M.; Siegrist, M. The importance of food naturalness for consumers: Results of a systematic review. Trends Food Sci. Technol. 2017, 67, 44-57. [CrossRef]

29. Ajzen, I. The theory of planned behaviour: Reactions and reflections. Psychol. Health 2011, 26, 1113-1127. [CrossRef]

30. Smith, M.L. Cities The First 6000 Years; Viking: New York, NY, USA, 2019; p. 285.

31. Corsini, F.; Laurenti, R.; Meinherz, F.; Appio, F.P.; Mora, L. The Advent of Practice Theories in Research on Sustainable Consumption: Past, Current and Future Directions of the Field. Sustainability 2019, 11, 341. [CrossRef]

32. Specht, K.; Zoll, F.; Schümann, H.; Bela, J.; Kachel, J.; Robischon, M. How Will We Eat and Produce in the Cities of theFuture? From Edible Insects to VerticalFarming-A Study on the Perception andAcceptability of New Approaches. Sustainability 2019, 11, 4315. [CrossRef]

33. Ramzi, M.; Hussain, M.; Yusoff, N.H.; Tukiman, I.; Samah, M.A.A. Mohd Ramzi Mohd Hussain, Norul Hafizah Yusoff, Izawati Tukiman, Mohd Armi Abu Samah Community Perception and Participation of Urban Farming Activities. Int. J. Recent Technol. Eng. 2019, 8, 341-345.

34. Sanyé-Mengual, E.; Specht, K.; Krikser, T.; Vanni, C.; Pennisi, G.; Orsini, F.; Gianquinto, G.P. Social acceptance and perceived ecosystem services of urban agriculture in Southern Europe: The case of Bologna, Italy. PLoS ONE 2018, 13, e0200993. [CrossRef] [PubMed] 